\title{
Normowanie prac spawalniczych przy spawaniu orbitalnym
}

\author{
Standardization of welding \\ in the orbital welding
}

\section{Streszczenie}

W artykule opisano przykłady normowania prac spawalniczych przy spawaniu orbitalnym. Podano orientacyjne czasy spawania dwóch reprezentatywnych połączeń oraz przeanalizowano cały proces spawania orbitalnego. Przedstawiono ponadto wstępne kryteria doboru głowic orbitalnych z uwzględnieniem spawania wielogłowicowego. Porównano czasy jarzenia się łuku podczas spawania orbitalnego do innych metod spawania.

Słowa kluczowe: spawanie orbitalne; techniczna norma czasu pracy; normowanie spawania orbitalnego

\section{Abstract}

Examples of standardization of welding in the orbital welding process are described in the above article. Approximate times of welding two representative joints and an analysis of the process of orbital welding is provided. Furthermore, pre-selection criteria of a choice of orbital welding heads taking into account the multi-head welding are given. Arcing time during orbital welding is compared to other welding methods.

Keywords: orbital welding; technical standard of working time; standardization of orbital welding

\section{Wstęp}

W prasie branżowej nie poświęcono dotychczas wiele miejsca zagadnieniom związanym z normowaniem prac spawalniczych przy spawaniu orbitalnym. W związku ze zwiększeniem wymagań jakościowych dotyczących spawania, zwłaszcza w przemyśle spożywczym, farmaceutycznym lub lotniczym wzrasta liczba spawarek orbitalnych obecnych na rynku. W niektórych przypadkach nie dopuszcza się w ogóle spawania ręcznego. Ponadto sterowanie źródłami prądu do spawania orbitalnego realizowane jest w sposób nieco inny niż ma to miejsce przy spawaniu ręcznym, ponieważ mając możliwosc precyzyjnego prowadzenia elektrody wolframowej można $w$ bardzo dokładny sposób kontrolować czas impulsów prądu w zakresie +/- 0,1s. Wymierną korzyścią, jaką daje spawanie orbitalne oprócz podniesienia jakości, to możliwość zastąpienia spawacza operatorem. Taki podział obowiązków sprawia, że wykwalifikowany spawacz może wykonywać inne połączenia, operator podczas pracy urządzenia przy właściwej organizacji stanowiska pracy może realizować czynności np. przygotowawczo - zakończeniowe lub pomocnicze.

Na rynku istnieje kilku producentów urządzeń do spawania orbitalnego, ale wszystkie one zbudowane są modułowo w podobny sposób. W ich skład wchodzą:

- źródło prądu spawania

- układ sterujący

- układ chłodzący

- głowica do spawania

- urządzenia peryferyjne.

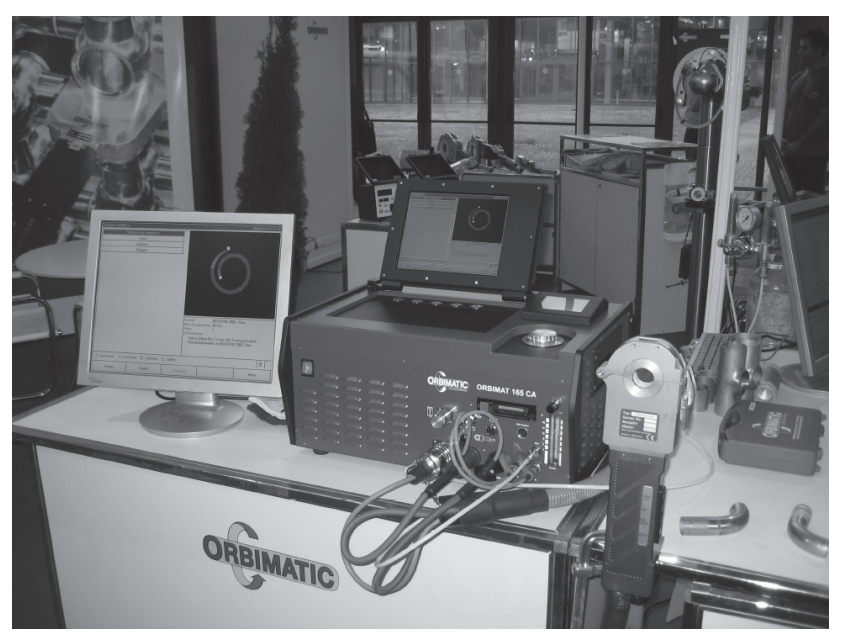

Rys. 1. Zestaw do spawania orbitalnego Fig. 1. A unit for orbital welding

Na rysunku 1 przedstawiono przykładowy zestaw do spawania orbitalnego składający się ze źródła prądu zintegrowanego z układem sterującym oraz głowicy zamkniętej z wymiennymi wkładkami mocującymi.

Głowice do spawania orbitalnego dzielą się na głowice otwarte, zamknięte oraz do spawania rur do den sitowych w wymiennikach ciepła. Istniejąjeszcze głowice w wykonaniach specjalnych, ale znajdują one zastosowanie w pojedynczych

Dr hab. Inż. Jacek Słania, prof. PCz - Politechnika Częstochowska, mgr inż. Piotr Malczewski - Orbitalum Tools GmbH. Autor korespondencyjny/Corresponding author: jacek_slania@poczta.onet.pl 
aplikacjach i nie odgrywają znaczącej roli w spawaniu orbitalnym. Modyfikacje te jednak pozwają na spawanie nietypowych złączy lub spawanie w sytuacji, kiedy dostęp do miejsca spawania jest ograniczony co ilustrują rysunek $2 a$ oraz $2 \mathrm{~b}$, gdzie przekonstruowanie systemu zamknięcia głowicy sprawiło, że do spawania można było zastosować głowicę orbitalną.
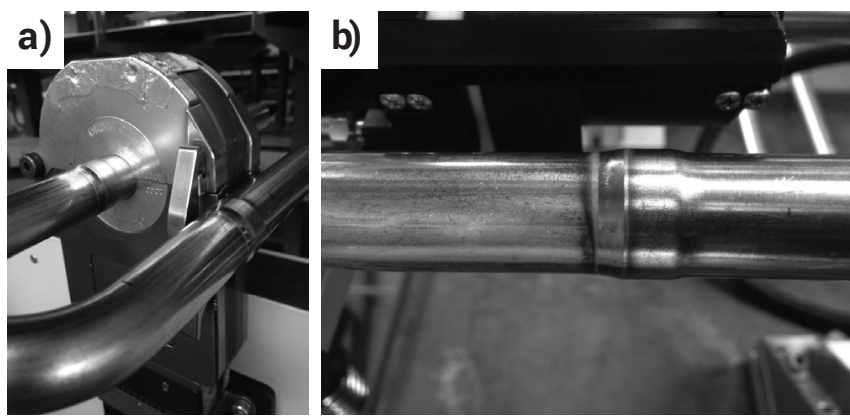

Rys. 2. a) głowica orbitalna z przesuniętymi o $90^{\circ}$ zaciskami; b) spoina wykonana orbitalnie dzięki modyfikacji konstrukcyjnej głowicy Fig. 2. a) an orbital head with clamps moved by $90^{\circ} ;$ b) an orbital weld made by modifying the design of the head

Bardzo ważną rolę podczas spawania odgrywa organizacja produkcji. Ma ona znaczący wpływ zarówno na koszty, jak i na czas wykonania prac spawalniczych.

$\mathrm{Na}$ proces spawania orbitalnego składa się z reguły czas przygotowania rur lub innych elementów takich jak różnego rodzaju złączki, kołnierze itp., oraz czas samego spawania.

Przygotowanie rur do spawania składa się z następujących operacji:

- cięcie rur do odpowiedniej długości,

- planowanie lub fazowanie rur jeśli wymaga tego proces spawania,

- przygotowanie krawędzi - czyszczenie i odtłuszczanie

- ewentualne sczepianie elementów,

- transport przygotowanych rur na stanowisko spawania orbitalnego.

Proces spawania orbitalnego składa się z następujących operacji:

- jednorazowo przed każdym spawaniem - kontrola urządzenia, stanu elektrody, wybór odpowiedniego programu spawania,

- mocowanie rur w głowicy spawalniczej (lub głowicy na rurze w przypadku głowicy otwartej)

- uruchomienie procesu spawania

Normowanie procesu spawania orbitalnego zależy w początkowej fazie od wyboru głowicy i sposobu mocowania elementów spawanych. Podczas doboru właściwego sprzętu, należy mieć na uwadze to, że dość często projektowane połączenie może być spawane kilkoma różnymi głowicami z grupy głowic zamkniętych, jak i otwartych. Czasami korzystniej jest kilka połączeń wykonać głowicą otwartą (nawet jeśli trzeba wcześniej wykonać operację sczepiania), żeby uniknąć kłopotliwej wymiany elektrody i zacisków mocujących. Jeśli specyfika produkcji pozwala na zastosowanie wielu różnych typów głowic, wybór właściwej należy oprzeć na oszacowaniu profilu produkcji w przyszłości.

\section{Techniczna norma czasu spawania $T_{n}$}

Techniczna norma czasu spawania $T_{n}$ to obiektywnie niezbędny czas potrzebny na wykonanie operacji spawania, przy założeniu normalnych i racjonalnych warunków pracy. Techniczną normę czasu będącą sumą czasu przygotowawczo - zakończeniowego i czasu jednostkowego obejmującego czas wykonania oraz czas uzupełniający, przedstawiono na rysunku 3 [1].

W przypadku spawania orbitalnego na czas wykonania $t_{w}$ składa się czas główny $t_{g}$ ( $w$ tym przypadku czas jarzenia się łuku wraz ze wstępnym i końcowym czasem przepływu gazu) oraz czas pomocniczy $t_{p}$, który jest niezbędny jest do wymiany elementu spawanego oraz jego zamocowania w głowicy orbitalnej.

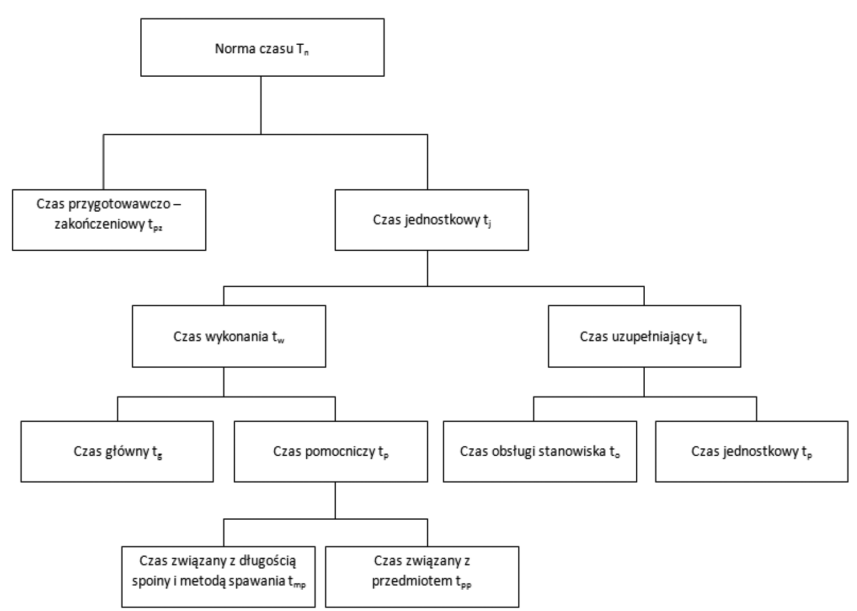

Rys. 3. Struktura technicznej normy czasu spawania [1]

Fig. 3. A structure of the technical standard of the welding time [1]

Szczegółowy schemat czasu głównego podczas spawania orbitalnego przedstawia rysunek 4. Czas związany ze wstępnym i końcowym przepływem gazu jest stały niezależnie od średnicy spawanych rur, w związku z tym współczynnik czasu jarzenia się łuku jest tym wyższy, im większa jest średnica elementów.

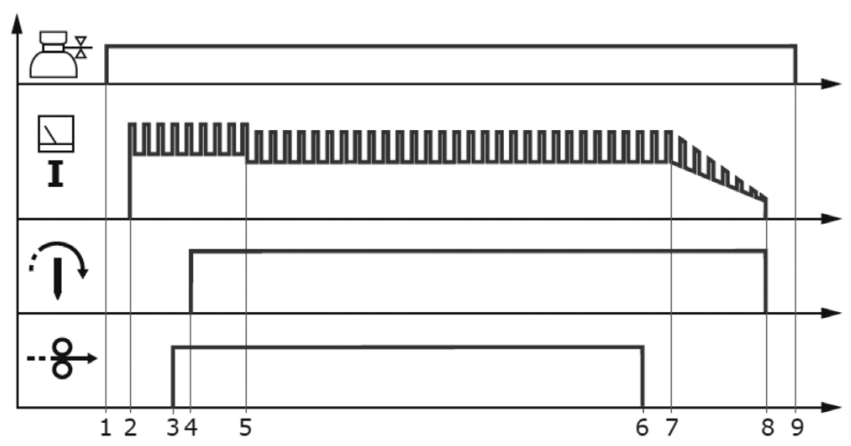

Rys. 4. Fazy procesu spawania orbitalnego [2]

Fig. 4. Phases of the orbital welding process [2]

Jak wynika z powyższego rysunku, wyodrębnić można następujące fazy spawania orbitalnego:

1. Wstępny przepływ gazu.

2. Zajarzenie łuku, tworzenie jeziorka spawalniczego.

3. Rozpoczęcie posuwu drutu spawalniczego (opcjonalnie).

4. Początek ruchu obrotowego elektrody.

5. Zmiana parametrów w czasie spawanie (programowanie niezależnych sektorów).

6. Zatrzymanie posuwu drutu.

7. Stopniowe wzgaszanie łuku.

8. Koniec procesu spawania i zatrzymanie ruchu elektrody

9. Zatrzymanie końcowego przepływu gazu.

W przypadku spawania orbitalnego rur ze stali $316 \mathrm{~L}$ o średnicy $28 \mathrm{~mm}$ i grubości ścianki 1,5 mm przyjąć należy następujące składowe czasu głównego, bazując na powyższym schemacie (pominąwszy punkty 3 oraz 6 , ponieważ 
a)

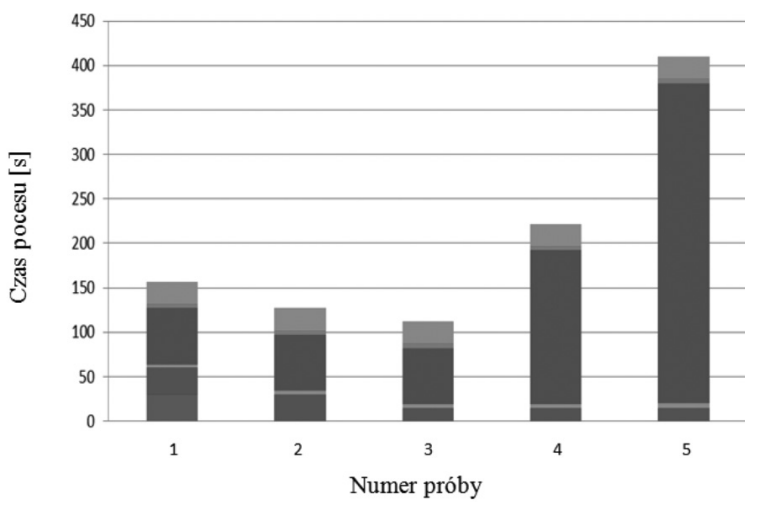

b)

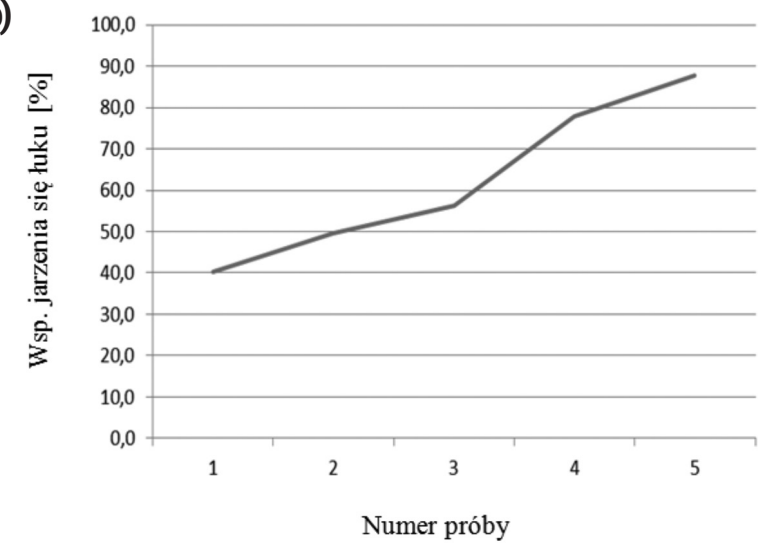

Legenda do wykresów:

1. Średnica $28 \mathrm{~mm}$ bez FlowForce, spawanie jednogłowicowe

2. Średnica $28 \mathrm{~mm}$ bez FlowForce, spawanie dwugłowicowe

3. Średnica 28 z FlowForce, spawanie dwugłowicowe

4. Średnica $77 \mathrm{~mm}$ z Flow Force, spawanie dwugłowicowe

5. Średnica $160 \mathrm{~mm}$ z FlowForce, spawanie dwugłowicowe

Rys. 5. a) wzrost współczynnika jarzenia się łuku wraz ze wzrostem średnicy spawanych elementów; b) wzrost współczynnika jarzenia się tuku wraz ze wzrostem średnicy spawanych elementów

Fig. 5. a) an increase of the arcing factor in relation to an increase of a diameter of welded parts; b) an increase of the arcing factor in relation to an increase of a diameter of welded parts

w tym przypadku spawanie następuje poprzez stopienie materiału rodzimego):

- wstępny przepływ gazu (1) - $30 \mathrm{~s}$,

- zajarzenie łuku (2) - 3,8 s,

- rozpoczęcie i zakończenie obrotu elektrody wewnątrz głowicy z uwzględnieniem zakładki (spawanie do 370stopni) oraz wygaszenia łuku: (4) do (8) - $64 \mathrm{~s}$,

- końcowy przepływ gazu: (8) do (9) - $20 \mathrm{~s}$,

- wymiana elementu wraz z mocowaniem nowego: 30s (jeśli spawanie jest w konfiguracji dwugłowicowej, wtedy czynności te są wykonywane podczas spawania).

Jak wynika z powyższych obliczeń, czas wykonania połączenia rury $z$ rurą $w$ konfiguracji jednogłowicowej wynosi 156,8 s, natomiast współczynnik czasu jarzenia się łuku w stosunku do czasu wykonania wynosi $40,2 \%$. W urządzeniach dostępnych obecnie na rynku, np. w źródłach prądu Orbimat 165/300 CA firmy Orbitalum Tools istnieje możliwość zwiększenia tego współczynnika poprzez zastosowanie funkcji FlowForce umożliwiającej skorzystanie z niezależnego kanału gazowego i skrócenia czasu wstępnego przepływu gazu (1) do (2) na rysunku 4 nawet do $15 \mathrm{~s}$, co sprawia że $w$ analizowanym przypadku współczynnik rośnie z $40,2 \%$ do $44,4 \%$. Jak wspomniano wcześniej wzrasta on również wraz ze wzrostem średnic spawanych elementów.

W przypadku rury ze stali $316 \mathrm{~L}$ o średnicy $77 \mathrm{~mm}$ i grubości ścianki 1,5 mm przykładowy rozkład czasów przedstawia się następująco:
- wstępny przepływ gazu (1) - $30 \mathrm{~s}$,

- zajarzenie łuku (2) - 3,8 s,

- rozpoczęcie i zakończenie obrotu elektrody wewnątrz głowicy z uwzględnieniem zakładki (spawanie do 370 stopni) oraz wygaszenia łuku: (4) do (8) - 178,1 s,

- końcowy przepływ gazu: (8) do (9) - 20 s.

Parametry spawania są w obu przypadkach takie same, tzn. element spawany jest prądem pulsacyjnym o górnej wartości $52 \mathrm{~A}$ i dolnej 26 A oraz częstotliwości impulsów 0,15 s.

Na rysunku 5 przedstawiono rozkład czasu spawania orbitalnego z uwzględnieniem funkcji FlowForce, spawania dwugłowicowego oraz średnic 28 mm (1-3), 77 mm (4) i 160 mm (5).

Jak widać na powyższym rysunku, decydując się na spawanie dwugłowicowe, możliwe jest skrócenie czasu spawania. Zmiana taka generuje jednak spore koszty w postaci urządzenia rozdzielającego, którego cena stanowi zazwyczaj 20-30\% ceny źródła prądu oraz konieczność posiadania dwóch głowic spawalniczych. Opłacalność takiego rozwiązania maleje również wraz ze wzrostem średnic spawanych elementów i musi być ściśle skorelowana z liczbą spoin w cyklu dziennym (zmianowym).

Przykład spawania wielogłowicowego ilustruje rysunek 6. W aplikacji tej zastosowano trzy źródła prądu oraz sześć głowic spawalniczych ze względu na dużą ilość rur w spawanym wymienniku ciepła. Poniższy proces został zaplanowany w taki sposób, że wszystkie głowice obsługiwane są przez jednego operatora. Przy mniejszych wymiennikach stosuje się najczęściej dwie lub cztery głowice. Dodatkową zaletą spawania dwugłowicowego jest możliwość podłączenia dwóch różnych głowic do jednego źródła prądu i naprzemienne spawanie np. cienkich elementów głowicą zamkniętą bez podawania materiału dodatkowego a bezpośrednio po skończonym procesie spawania natychmiastowe rozpoczęcie procesu spawania np. głowicą otwartą lub specjalną. Pozwala to dodatkowo zwiększyć efektywność spawania.

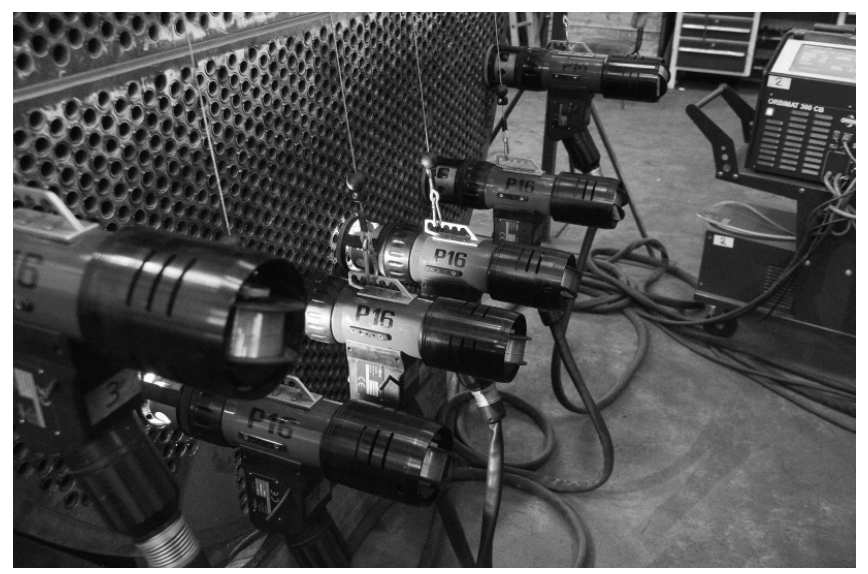

Rys. 6. Spawanie orbitalne wielogłowicowe

Fig. 6. An orbital multi-head welding

Stosunek jarzenia się łuku do czasu wykonania waha się w granicach od $40,2 \%$ do $87,7 \%$., co sprawia, że proces spawania orbitalnego mieści się $\mathrm{w}$ górnym zakresie spawania zautomatyzowanego, a nawet przy spawaniu dwugłowicowym w zakresie spawania zrobotyzowanego, co przedstawiono na rysunku 8.

Jak wspomniano powyżej, istnieją na rynku rozwiązania pozwalające podłączyć dwie głowice orbitalne do jednego źródła prądu i spawać naprzemienne. W przypadku, jeśli operator jest w stanie wykonać wszystkie czynności związane z przygotowaniem elementu do spawania w czasie mniejszym od czasu głównego, urządzenie wykorzystywane jest w sposób optymalny.

Współczynnik jarzenia się łuku jest istotnym parametrem porównawczym określającym stopień automatyzacji danej 


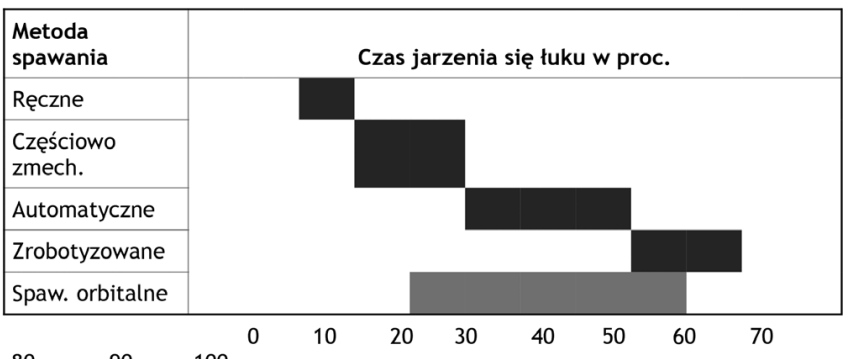

$80 \quad 90 \quad 100$

Rys. 8. Czas jarzenia się łuku podczas spawania orbitalnego w porównaniu do innych metod spawania [1]

Fig. 8. An arcing time during orbital welding compared to other welding methods [1]

metody spawania, należy jednak mieć na uwadze, że z punktu widzenia użytkownika najistotniejszym wskaźnikiem jest czas wykonania, który może ulec skróceniu np. poprzez wzrost prędkości spawania przy automatycznym zmniejszeniu współczynnika $\mathrm{W}_{\mathrm{j}}$.

W spawaniu orbitalnym efekt taki uzyskać można stosując zamiennie do argonu gaz z domieszką wodoru lub poprzez zastosowania topnika aktywującego A-TIG. Należy ponadto zauważyć, że nie istnieją sztywne parametry spawania orbitalnego. Dobór ich w dużej mierze polega na doświadczeniu operatora oraz na wykonaniu złączy próbnych i jest efektem współgrania takich parametrów jak prędkość obrotowa elektrody, prąd spawania, częstotliwość trwania wysokiego i niskiego impulsu prądu oraz czynników dodatkowych takich jak czystość i rodzaj gazu osłonowego i formującego, rodzaj i kąt oszlifowania elektrody wolframowej, odległości elektrody od materiału podczas spawania. Osobną kwestią jest fakt właściwego przygotowania rur do spawania - ma to wpływ zarówno na dobór parametrów, jak i szybkość zużycia się elektrody i przyspiesza konieczność jej ponownego ostrzenia.

\section{Podsumowanie}

W związku z trendem zmierzającym do wzrostu mechanizacji i automatyzacji spawania, spawanie orbitalne będzie odgrywało coraz większą rolę w różnych gałęziach przemysłu. Ze względu na szeroki wachlarz zastosowań począwszy od mikrozłączek w przemyśle chemicznym lub farmaceutycznym, a na przemyśle stoczniowym kończąc, istnieje duża liczba potencjalnych zastosowań. Jak wynika z powyższego tekstu, przy spawaniu dwugłowicowym i właściwej organizacji produkcji można uzyskać stopień mechanizacji porównywalny nawet ze spawaniem zrobotyzowanym, co w połączeniu z brakiem wysoko wykwalifikowanej kadry spawalniczej, sprawia że metoda spawania orbitalnego posiada coraz większy udział w rynku i mając na uwadze jej powtarzalność i wysoką jakość uzyskanych połączeń zastępuje ona z powodzeniem spawanie ręczne.

\section{Literatura}

[1] Praca zbiorowa: Poradnik Inżyniera, Spawalnictwo, Tom 1, WNT Warszawa 2003.

[2] Praca zbiorowa: The orbital welding handbook, Polysoude Nantes France SAS, 2009

[4] Nowacki J., Pakos R., Kosek S.: Komputerowe wspomaganie obliczeń kosztów spawania, Przegląd Spawalnictwa, nr 4/2007.

[3] Zeman W.: Źródła obniżania kosztów w spawalnictwie, Biuletyn Instytutu Spawalnictwa nr 5/2000. 